\title{
Proposta metodológica para mapeamento da vulnerabilidade socioambiental: caso do município de Belém, Pará, Brasil
}

A vulnerabilidade socioambiental congrega um conjunto de fatores ambientais e sociais que podem diminuir ou aumentar o (s) risco (s) no qual o ser humano, individualmente ou em grupo, está exposto nas diversas situações da sua vida. Neste contexto, este artigo objetiva desenvolver uma metodologia que possibilite mapear este fenômeno, tendo como estudo de caso o município de Belém. Deste modo, por meio da análise integrada, usando ferramentas de geoprocessamento, dos mapas de vulnerabilidade ambiental e social identificaram-se as áreas com incidência de alta vulnerabilidade socioambiental. Estes lugares configuram-se, em sua maioria, pela ocupação irregular de locais de alta vulnerabilidade ambiental pela população em situação desfavorável no tocante à renda per capita, educação e moradia, como por exemplo, a invasão de dunas móveis e planícies fluviais. Nessa perspectiva, o mapeamento da vulnerabilidade socioambiental visa contribuir para o planejamento de ações que proporcionem o desenvolvimento sustentável, subsidiando, efetivamente, o processo de planejamento territorial.

Palavras-chave: SIG; Vulnerabilidade socioambiental; Planejamento territorial.

\section{Methodological proposal for mapping socio-environmental vulnerability: the case of the municipality of Belém, Pará, Brazil}

The socio environmental vulnerability brings together a set of environmental and social factors that can decrease or increase the risk (s) in which the human being individually or in groups, are exposed in the different situations of your life. In this context, this article aims to develop a methodology that makes it possible to map this phenomenon, taking as a case study the city of Belém. Thus, through integrated analysis using geoprocessing tools, the environmental and social vulnerability maps identified the areas with high incidence of socio environmental vulnerability. These places constitute themselves, mostly by illegal occupation of areas of high environmental vulnerability for the population at unfavorable situation regarding per capita income, education, and housing, such as the invasion of mobile dunes and river plains. In this perspective, the mapping of socio environmental vulnerability aims to contribute to the planning of actions that provide sustainable development, supporting, effectively, land use planning process in the city.

Keywords: GIS; Socio environmental vulnerability; Territorial planning.

Topic: Desenvolvimento, Sustentabilidade e Meio Ambiente

Reviewed anonymously in the process of blind peer.
Received: 03/03/2021

Approved: 26/03/2021
Leoni de Souza Belato (iD Instituto Tecnológico Vale, Brasil http://orcid.org/0000-0002-9230-2246 leonibelato@gmail.com

Sérgio Luis Cardoso Serrão (iD) Universidade Federal do Pará, Brasil http://orcid.org/0000-0002-0803-2627 seuserrao@gmail.com

Rayana Garcia de Amorim Universidade Federal do Pará, Brasil http://orcid.org/0000-0001-7809-595X rayana.garcia@gmail.com
Rosana Coelho (iD

Universidade Federal do Pará, Brasil http://orcid.org/0000-0002-4572-9888 rosanacoelho16@gmail.com

Rafael Pompeu Dias Universidade Federal do Pará, Brasil http://orcid.org/0000-0002-9744-0373 rafaelp.dias@yahoo.com.br

Ana Carla Capacio Cordeiro Universidade Federal do Pará, Brasil anacapacio@hotmail.com

Laís Moreira
Universidade Federal do Pará, Brasil
http://orcid.org/0000-0003-3456-6996
laismoreira@gmail.com
Diego Andrade 10
Instituto Tecnológico Vale, Brasil
http://orcid.org/0000-0003-3490-6452
engenheirodiegoandrade@gmail.com
Fernanda Lemos
Instituto Tecnológico Vale, Brasil
fernandalemos@gmail.com

Thaissa Juca Jardim Oliveira (iD) Universidade Federal de Ouro Preto, Brasil http://orcid.org/0000-0002-1896-5025 jardim.thaissa@gmail.com

Raimara Rosário

Universidade Federal do Pará, Brasil http://orcid.org/0000-0003-0502-2420 raimara.reis.rr@gmail.com

\section{Giovana Miranda}

Universidade Federal do Pará, Brasil http://orcid.org/0000-0002-0203-500X giovanamiranda1@outlook.com.br

\section{Referencing this:}

BELATO, L. S.; SERRÃO, S. L. C.; AMORIM, R. G.; COELHO, R.; DIAS, R. P.; CORDEIRO, A. C. C.; MOREIRA, L.; ANDRADE, D.; LEMOS, F.; OLIVEIRA, T. J. J.; ROSÁRIO, R.; MIRANDA, G.. Proposta metodológica para mapeamento da vulnerabilidade socioambiental: caso do município de Belém, Pará, Brasil. Revista Ibero Americana de Ciências Ambientais, v.12, n.3, p.554-569, 2021. DOI: http://doi.org/10.6008/CBPC2179-6858.2021.003.0045 


\section{INTRODUÇÃO}

Nas áreas urbanas existe uma tendência mundial de aglomeração populacional devido ao acelerado processo de urbanização que vem ocorrendo nas últimas décadas. No caso do Brasil, a transição demográfica do meio rural para o urbano vem promovendo profundas mudanças na distribuição das pessoas no território.

Santos (2008) afirma que até a primeira metade do século XX o país era uma nação com população predominantemente rural, e que entre 1940 e 1980 é que se dá a verdadeira inversão do lugar de residência. Segundo os dados dos censos demográficos do Instituto Brasileiro de Geografia e Estatística (IBGE), o contingente populacional urbano passou de $25 \%$ do total em 1940 para chegar a mais de $67 \%$ em 1980 . Atualmente mais de $80 \%$ da população brasileira reside em áreas urbanas ocasionando uma série de demandas por infraestrutura, bem como gerando impactos socioambientais. Neste viés de análise, menciona-se que a vulnerabilidade social decorre de vários fenômenos, com causas e consequências distintas, os quais podem atingir de forma desigual a população residente em um determinado local.

Segundo Zanella et al. (2013), as condições demográficas, culturais, políticas, econômicas e educacionais influenciam as pessoas, ou territórios contendo grupos de indivíduos, a estarem na situação de maior ou menor vulnerabilidade, isto é, refletem a capacidade de enfrentar os riscos e aproveitar as oportunidades visando melhorar a situação de bem-estar, ou impedir a sua deterioração.

Para Tominaga (2009), a vulnerabilidade corresponde a um conjunto de processos e condições resultantes de fatores ambientais, biológicos, sociais, econômicos e políticos que aumentam a suscetibilidade ao impacto de um determinado risco.

Penna et al. (2014) definem a vulnerabilidade como um risco social, caracterizando-se pela concentração da precariedade (ou falta) de serviços coletivos e de investimentos públicos em infraestruturas (os ativos e as estruturas de oportunidades), que desse modo provocam a desproteção social das comunidades mais carentes. A vulnerabilidade pode ou não estar associada a riscos ambientais, como, por exemplo, moradias localizadas em áreas de alta declividade (perigo de deslizamentos e soterramentos de pessoas e habitações) ou sujeitas a enchentes.

Em relação à vulnerabilidade ambiental, a mesma refere-se ao conjunto integrado de fatores ambientais (ecológicos e biológicos) que diante de atividades humanas, ocorrentes ou que venham se manifestar, poderá sofrer alterações afetando, total ou parcialmente, a estabilidade ecológica de um local.

Neste contexto, a vulnerabilidade ambiental pode ser compreendida a partir da análise das características ecodinâmicas dos sistemas ambientais, relacionando também à capacidade de resposta do meio físico aos efeitos adversos provocados por ações antropogênicas (SOUZA, 2000; TAGLIANI, 2002; SANTOS et al., 2007).

Por sua vez, a vulnerabilidade socioambiental congrega a vulnerabilidade ambiental e social de forma simultânea, materializando-se em certo território num dado recorte temporal (DESCHAMPS, 2004). Segundo Santos (2015), o entendimento da vulnerabilidade socioambiental passa necessariamente pelo conhecimento das condições morfodinâmicas dos sistemas ambientais. Os riscos socioambientais, contudo, 
não podem ser definidos somente com suporte em aspectos naturais, eles constituem a associação desses fenômenos com a capacidade de proteção dos grupos sociais, ou seja, da vulnerabilidade social.

Nesse sentido, a vulnerabilidade socioambiental corresponde a um local onde coexistem ambientes e populações em situação de risco, expondo os indivíduos às adversidades (perigos) decorrentes de fenômenos naturais e sociais, tais como inundações ou enchentes, deslizamentos de terra, soterramentos, erosão marinha, secas recorrentes, acometimentos de doenças, perdas de emprego, recessão econômica, entre outras.

Nesse sentido, o trabalho objetiva mapear vulnerabilidade socioambiental, a partir da análise integrada da vulnerabilidade ambiental e da vulnerabilidade social, tendo como estudo de caso o município de Belém (Figura 1), Estado do Pará. Nesse sentido, as informações resultantes da correlação entre esses aspectos constituirão uma importante base de dados, que poderá ser utilizada para o ordenamento territorial urbano pautado nas diretrizes do desenvolvimento sustentável.

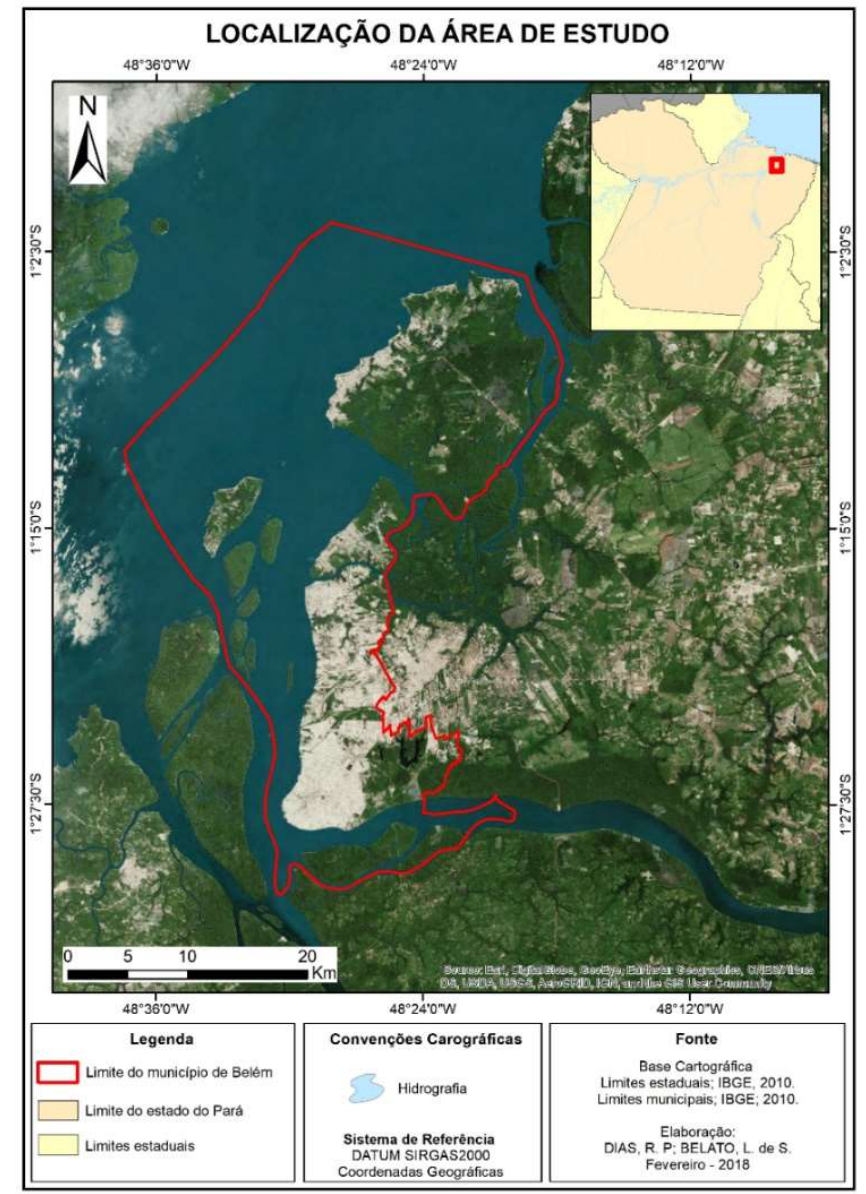

Figura 1: Localização do município de Belém/PA.

\section{METODOLOGIA}

\section{Materiais e procedimentos operacionais}

Para a compreensão e operacionalização da vulnerabilidade socioambiental, optou-se pela determinação de etapas, analisando inicialmente a vulnerabilidade ambiental e social do município de Belém de forma separada. Após isto, visando mapear os locais de ocorrência da vulnerabilidade socioambiental, 
realizou-se, por meio de técnicas de geoprocessamento, a análise integrada da vulnerabilidade social e ambiental. A seguir, são descritos os procedimentos operacionais e os materiais utilizados nesta pesquisa.

\section{Vulnerabilidade Social}

Em relação aos dados sociais e econômicos pesquisados, a principal fonte utilizada foi o censo demográfico do IBGE referente ao ano de 2010. A base territorial empregada para o estudo da vulnerabilidade social (IVS) foi em nível de distritos e setores censitários.

Destaca-se que o emprego de um índice de vulnerabilidade social constitui-se em uma importante ferramenta ao possibilitar a identificação de desigualdades sócio territoriais. Isto se torna possível porque o IVS permite uma representação aproximada das condições de vida da população inserida em um determinado território.

Para tanto, a elaboração do IVS requer uma escolha cuidadosa dos indicadores que serão utilizados, considerando, inclusive, a disponibilidade de dados e os critérios que possam retratar as condições socioeconômicas e os aspectos da urbanização que envolve diferentes grupos sociais (SANTOS, 2015).

Neste contexto, com base na definição de ativos conceituada por Kaztman (1999) e nos estudos de Medeiros et al. (2005), Cunha et al. (2006), SEMAS (2009), Macedo et al. (2010), Macedo et al. (2012), SEADE (2012), PNUD (2013) e Santos (2015), foram propostos indicadores e dimensões para a concepção do IVS (Quadro 1).

Quadro 1: Síntese dos indicadores que compõem o IVS segundo dimensões.

\begin{tabular}{|c|c|c|c|}
\hline Habitação e Saneamento & Renda & Educação & Situação Social \\
\hline $\begin{array}{l}\% \text { de moradores em domicílios } \\
\text { próprios. } \\
\% \text { de moradores em domicílios ligados } \\
\text { à rede geral de água. } \\
\% \text { de moradores em domicílios com } \\
\text { existência de banheiro ou sanitário. } \\
\% \text { de moradores em domicílios ligados } \\
\text { à rede geral de esgoto ou com fossa } \\
\text { séptica. } \\
\% \text { de moradores em domicílios com } \\
\text { lixo coletado por serviço de limpeza. } \\
\% \text { de moradores em domicílios com } \\
\text { energia elétrica. }\end{array}$ & $\begin{array}{l}\text { - Renda média mensal } \\
\text { domiciliar. } \\
\text { - \% de domicílios com renda } \\
\text { per capita inferior a } 1 \frac{1}{2} \text { salário } \\
\text { mínimo. }\end{array}$ & $\begin{array}{l}\text { \% de chefes de domicílio } \\
\text { analfabetos. } \\
\text { Média de moradores por } \\
\text { domicílio. }\end{array}$ & $\begin{array}{l}\text { - \% de mulheres } \\
\text { chefes de domicílios. } \\
\text { - \% de agregados à } \\
\text { família. }\end{array}$ \\
\hline
\end{tabular}

Na dimensão Habitação e Saneamento os indicadores procuram captar deficiências relacionadas aos serviços básicos de infraestrutura, assim como questões atinentes a propriedade do domicílio.

Buscou-se através dos indicadores da dimensão Renda apreender as condições de distribuição de renda, permitindo um possível acesso por parte das famílias a bens duráveis, alimentação, além de formas de seguro e proteção.

Por sua vez, os indicadores disponíveis na base de dados do Censo 2010 e utilizados na dimensão Educação pretenderam captar situações de precariedade do nível de escolaridade e consequentemente, dificuldades em buscar empregos com um maior nível salarial. 
Quanto à dimensão da Situação Social, procurou-se resgatar elementos ligados ao grau de dependência econômica e envelhecimento existente nas áreas de estudo, considerando que tais elementos podem refletir dificuldades para as famílias no processo de reprodução social. Abordou-se também a densidade domiciliar e as formações domésticas que poderiam prejudicar o bem-estar da família.

Desses quinze indicadores, oito têm uma relação direta com a vulnerabilidade social, são eles: \% de domicílios com renda domiciliar per capita inferior a 1⁄2 salário mínimo; Variância da renda média domiciliar; \% da população com 15 anos ou mais de idade analfabeta; \% de chefes de domicílios analfabetos; Média de moradores por domicílio; Razão de dependência; \% de mulheres chefes de domicílios; \% de agregados à família.

Nesse sentido, quanto maior o valor do indicador tende a ser mais vulnerável a população residente no setor censitário. Os demais indicadores têm uma relação inversa, isto é, quanto maior o valor do indicador, provavelmente menos vulnerável seja a população que habita em determinado setor censitário.

Utilizou-se a metodologia, proposta por um autor que descrever distribuições a partir da análise estratégica e exploração de dados de uma variável quantitativa. Considerando-se valores de 0 (menor vulnerabilidade) a 1 (maior vulnerabilidade), uma vez que se têm indicadores com diferentes unidades de medida, como por exemplo: percentual, valor monetário (R\$), média, entre outros. Desta forma, um indicador padronizado no setor censitário é obtido através da Fórmula 1:

$$
Z=\frac{X-\mu}{\sigma}
$$

Onde: $\alpha$-corresponde ao desvio padrão para um grande conjunto de dados; $\mu$-corresponde à média de um grande conjunto de dados; $x$ - corresponde a um valor determinado de um conjunto de dados;

Se $x$ tem a distribuição $N(X, S)$, então a variável padronizada $z=(x-\mu) / \alpha$ tem a distribuição normal padrão $N(0,1)$ com média zero e desvio padrão igual a 1 . O modelo normal é imprescindível para o desenvolvimento da amostragem, estimação por intervalos, e testes de hipóteses. A utilização de planilhas permite que o pesquisador seja capaz de trabalhar de uma forma dinâmica e interativa.

Após a padronização dos 15 indicadores que compõem o IVS, tem-se como resultado que os valores mais próximos de 1 refletem maior vulnerabilidade. Vale destacar que o Índice de Vulnerabilidade Social (IVS) é obtido pelo valor médio dos indicadores.

Posteriormente a elaboração do índice, foi realizada a classificação dos setores censitários do município de Caucaia, usando o programa ArcGIS 10.2, especificando cinco classes de vulnerabilidade, baseadas na média e na variabilidade (desvio-padrão) do IVS.

Desse modo, foram criadas as seguintes classes de vulnerabilidade: Muito alta - alta vulnerabilidade: Corresponde a valores superiores ao índice médio somado ao valor do desvio-padrão; média vulnerabilidade: Para valores maiores que o valor médio e menores que a média mais o valor do desvio-padrão; baixa-muito baixa vulnerabilidade: Para valores inferiores à média e superiores à média menos um desvio-padrão; Baixa vulnerabilidade: Corresponde a valores inferiores à média menos o valor de um desvio-padrão. 


\section{Sistemas Ambientais e Vulnerabilidade Ambiental}

Para estudar a vulnerabilidade ambiental do município de Belém, optou-se pela aplicação da análise ecodinâmica fundamentada na compreensão de estabilidade/instabilidade ambiental (TRICART, 1977). Nesse sentido, definem-se unidades ecodinâmicas a partir da análise dos processos de pedológicos e morfológicos. Essas unidades correspondem a uma esfera natural de território a funcionar com um sistema e, dessa maneira, manter diversos vínculos entre os componentes em um fluxo de energia e matéria que o distingue.

Para Tricart (1992), o entendimento sobre o comportamento do meio ambiente perpassa pelo estudo da morfodinâmica, método importante para a utilização racional dos recursos naturais e análise de riscos aos ambientes, quando susceptíveis às intervenções antropogênicas. Para a organização territorial é fundamental a aplicação da análise ecodinâmica, para elucidar a dinamicidade das ações humanas empregadas em determinado sistema ambiental, que por sua vez gera uma resposta específica à ação. Dessa maneira, permitindo o planejamento ambiental das ações de intervenção do homem sobre os sistemas ambientais, otimizando a utilização dos recursos naturais e diminuindo os processos socioeconômicos e culturais das sociedades modernas.

O mapa de vulnerabilidade ambiental de Belém foi elaborado a partir da integração dos índices de vulnerabilidade de cada atributo dos meios físico, biótico e das formas de uso do solo (Figura 2).

Os valores do grau de vulnerabilidade de cada atributo foram adaptados da metodologia empregada por Costa et al. (2006) e Maricato (2003). Utilizou-se na determinação do grau de vulnerabilidade de cada atributo a relação de predomínio entre os processos erosivos e pedogenéticos.

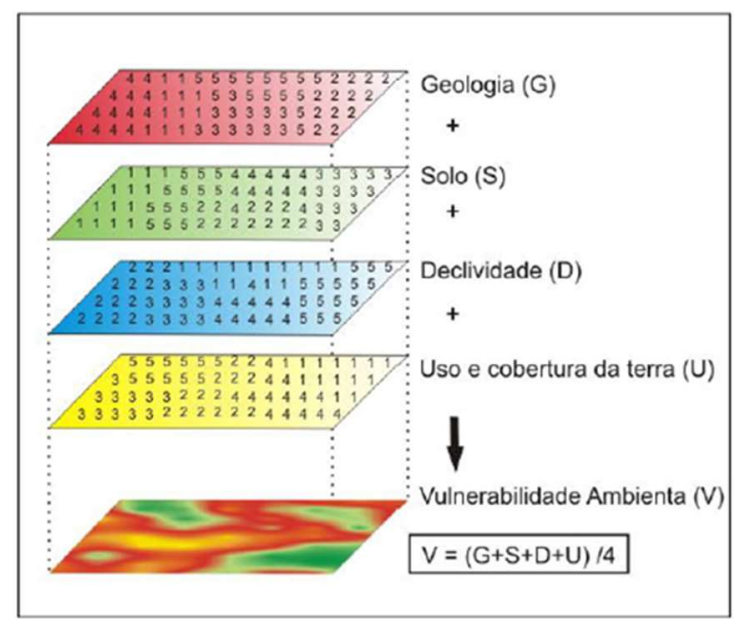

Figura 2: Roteiro para elaboração dos mapas de vulnerabilidade ambiental. Fonte: Adaptado de Costa et al. (2006).

Em cada classe, o grau de vulnerabilidade foi distribuído em uma escala de 1 a 3, com intervalos de 0,5. Com predominância da pedogênese, vulnerabilidade muito baixa, atribuiu-se o valor de 1 . Com o aumento da influência dos processos erosivos, o grau de vulnerabilidade aumenta até atingir o valor máximo, sendo 3, representando ambientes de vulnerabilidade muito alta (COSTA et al., 2006). A Tabela 1 apresenta o índice de vulnerabilidade de cada atributo ambiental. 
Tabela 1: Índice de vulnerabilidade natural e ambiental dos elementos da paisagem.

\begin{tabular}{|c|c|}
\hline Atributos Ambientais & Índice de Vulnerabilidade Natural e Ambiental \\
\hline \multicolumn{2}{|l|}{ Cobertura Vegetal } \\
\hline Floresta Ombrófila Densa Aluvial & 1 \\
\hline Floresta Ombrófila Densa Aluvial Com Dossez Uniformes & 1 \\
\hline Floresta Ombrófila Densa das Terras Baixas & 1 \\
\hline \multicolumn{2}{|l|}{ Pedologia } \\
\hline Corpos D'agua continentais & 1,5 \\
\hline Espodossolo Ferrihumilúvico Hidromórfico & 2 \\
\hline Plintossolo Pétrico Concrecionário & 3 \\
\hline Gleissolo Háplico tb Eutrófico & 3 \\
\hline Gleissolo Háplico tb Distrófico & 3 \\
\hline Latossolo Amarelo Distrófico & 1 \\
\hline \multicolumn{2}{|l|}{ Geologia } \\
\hline Corpos D'agua continentais & 3 \\
\hline Aluviões Holocênicos & 3 \\
\hline Formação Barreiras & 2 \\
\hline Cobertura Detrito-Lateritica Neo-Pleistocênica & 1 \\
\hline Cobertura Sedimetar do Baixo Tocantins & 1,5 \\
\hline Depósitos de Pantanos e Mangês Holocênicos & 3 \\
\hline \multicolumn{2}{|l|}{ Geomorfologia } \\
\hline Massa D'agua Continental & 1,5 \\
\hline Planicies Fluviomarinhas & 3 \\
\hline Tabuleiros Costeiros & 3 \\
\hline \multicolumn{2}{|l|}{ Uso e ocupação } \\
\hline Área Não Observada & 1 \\
\hline Área Urbana & 3 \\
\hline Floresta & 1 \\
\hline Hidrografia & 1 \\
\hline Mosaico de Ocupações & 2,5 \\
\hline Não Floresta & 2,5 \\
\hline Outros & 2,5 \\
\hline Pasto com Solo Exposto & 3 \\
\hline Pasto Limpo & 3 \\
\hline Pasto Sujo & 3 \\
\hline Regeneração Com Pasto & 1,5 \\
\hline Vegetação Secundária & 1,5 \\
\hline
\end{tabular}

Fonte: Adaptado de Costa et al. (2006).

Com isso, foram formadas cinco classes de vulnerabilidade com intervalos iguais. A Tabela 2 representa as classes de vulnerabilidades natural e ambiental, formadas pelos cruzamentos dos diversos atributos analisados.

Tabela 2: Classes da vulnerabilidade ambiental.

\begin{tabular}{l|l}
\hline Classes & Médias \\
\hline Muito Baixa & $0-0,85$ \\
\hline Baixa & $0,86-1,07$ \\
\hline Média & $1,08-1,40$ \\
\hline Alta & $1,41-1,85$ \\
\hline Muito Alta & $1,86-3$ \\
\hline
\end{tabular}

Para a confecção dos mapas foi utilizado o software Arcgis 10.5. Esse programa apresenta uma plataforma de SIG (Sistema de Informações Geográficas), possibilitando a manipulação de feições espaciais georreferenciadas associadas a um banco de dados com as informações analíticas, além de permitir o cruzamento entre os mapas produzidos.

Foram utilizados arquivos vetoriais em formato shapefile de vegetação, pedologia, geomorfologia e geologia, do ano de 2010, obtidos junto ao site do IBGE (Instituto Brasileiro de Geografia e Estatística), e os arquivos do mapeamento do uso do solo do projeto TERRACLASS, do ano de 2014, Orbita 223, Ponto 064, 
obtidos junto ao site do INPE (Instituto Nacional de Pesquisas Espaciais), os dados foram cruzados e transformados em arquivos de formato de saída RASTER, sua finalização se deu com a inclusão dos elementos cartográficos obrigatórios (fonte, legenda, orientação e escala).

\section{Vulnerabilidade Socioambiental}

Por meio de técnicas de análise espacial combinaram-se os mapas de vulnerabilidade ambiental e social, podendo-se localizar as áreas no município onde se situam a população mais vulnerável socialmente e ainda sofrem maiores riscos ambientais por ocuparem lugares com alta vulnerabilidade ambiental.

Como exemplo de estudos que utilizaram a cartografia e o geoprocessamento como ferramenta de integração da vulnerabilidade social e ambiental podem-se citar Cutter et al. (2000), Deschamps (2004), Zahran et al. (2008), Almeida (2012), Freitas et al. (2013), Zanella et al. (2013), Santos (2015), entre outros, justificando-se esta técnica por consentir-se a avaliação da localização de incidência do fenômeno da vulnerabilidade socioambiental de forma mais precisa.

Freitas et al. (2013) argumentam que na literatura que trata da vulnerabilidade já está consagrada a contribuição do geoprocessamento e do seu potencial para a modelagem de aspectos físicos e socioeconômicos, voltados à prevenção, mitigação e enfrentamento de manifestações de riscos, sejam eles naturais, sociais ou mistos.

Destarte, a cartografia da vulnerabilidade socioambiental permite a comparação entre os locais de um determinado território, contribuindo para uma melhor orientação de políticas voltadas para a prevenção, mitigação e sensibilização ao risco (MENDES et al., 2011).

Cunha et al. (2012) citam que o diagnóstico da vulnerabilidade socioambiental vem ganhando relevância na prática de planejamento do território, devido à mesma possibilitar a identificação de áreas prioritárias para a intervenção de políticas públicas com escopo para a conservação dos recursos naturais e para a elevação do bem-estar da população.

Isso posto, dá-se ênfase que o estudo da vulnerabilidade possibilita a identificação de ameaças presentes nas diferentes abordagens temáticas (social e ambiental). Por isso, a definição da vulnerabilidade origina importantes contribuições teórico-metodológicas para a análise dos possíveis efeitos causados pelos diversos riscos inseridos em um determinado território.

Por fim, cita-se que os dados vetoriais foram inseridos no programa ArcGIS 9.3, gerando um sistema de informação geográfica.

\section{RESULTADOS E DISCUSSÃO}

\section{Dinâmica dos processos naturais e a vulnerabilidade ambiental}

Foram definidas e delimitadas unidades de intervenção em virtude da vulnerabilidade ambiental, do grau de estabilidade do ambiente e da capacidade de suporte dos sistemas ambientais aos diversos usos da terra. Analisando os impactos ambientais nesse mapa (Figura 3) - nos termos do grau de suscetibilidade a 
situações de risco ambiental - podem-se prever as possíveis respostas do meio às intervenções, que variam de acordo com as características naturais e o uso do solo. A (Figura 3) apresenta também a distribuição percentual e área da vulnerabilidade ambiental.

A vulnerabilidade muito baixa, corresponde à maior unidade mapeada do município, que abrange aproximadamente $87 \%$ da área total. Está presente em áreas de vulnerabilidade ambiental baixa e muito baixa, associadas a ambientes com corpos D'agua ou recobertas por vegetação, portanto são áreas de melhor qualidade ambiental do município e as mais promissoras para a intervenção antrópica, uma vez que suas características proporcionam menores situações de risco ambiental, resguardadas as limitações e a legislação ambiental pertinente. Localiza-se principalmente no bairro Curió-Utinga e em pontos isolados pela cidade, chegando a ilha de Mosqueiro e outras ilhas dentro do limite municipal de Belém, representando áreas de vulnerabilidade natural muito baixa.

A vulnerabilidade baixa se estende por uma área de aproximadamente $6 \%$ do município. É formada por ambientes de vulnerabilidade Ambiental baixa ou mediana associados às áreas com vegetação. Apesar de apresentar vulnerabilidade baixa, essa unidade necessita de adoção de medidas de recuperação, controle e monitoramento ambiental, pois dentro dessas áreas de baixa vulnerabilidade encontram-se quatro Unidades de Conservação: Área de Proteção Ambiental de Belém, Área de Proteção Ambiental da Ilha do Combu, Refúgio de Vida Silvestre Metrópole da Amazônia e Parque Estadual do Utinga.

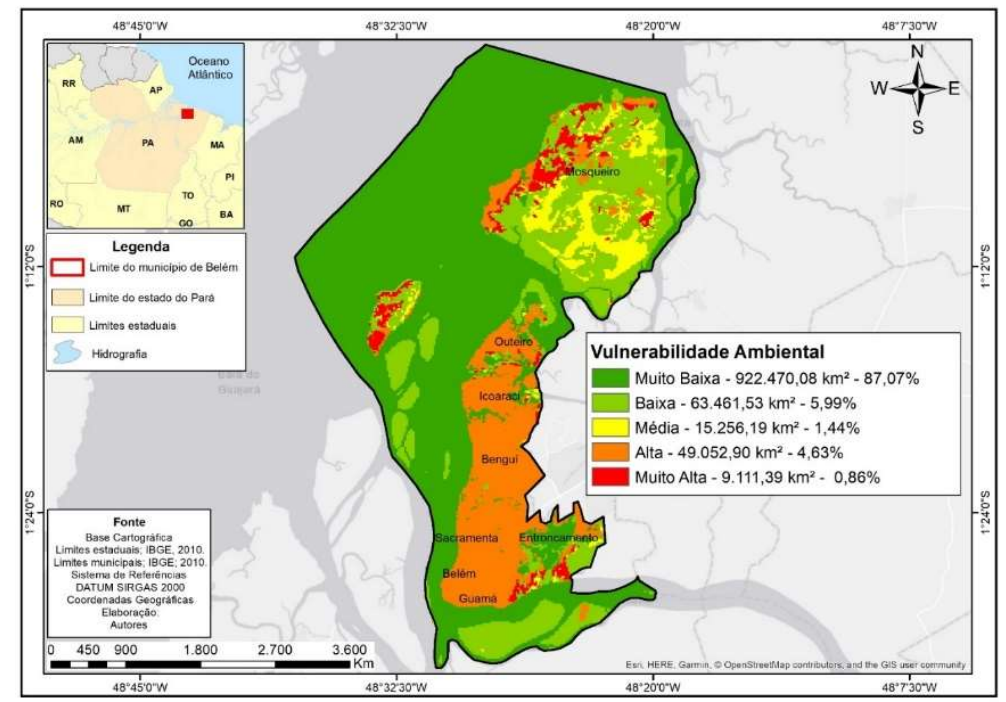

Figura 3: Mapa de vulnerabilidade ambiental do município de Belém/PA.

A vulnerabilidade média, encontra-se em apenas 1,44\% da área total pesquisada e distribui-se em manchas isoladas no interior do município e em suas ilhas, correspondendo a mosaicos, ora compostos por ambientes com vulnerabilidade ambiental muito alta associados a áreas com infraestrutura consolidada, ora constituindo ambientes de vulnerabilidade alta associados às áreas de infraestrutura precária, ou mesmo vulnerabilidade média com infraestrutura mediana. Devido às características diferenciadas entre os diversos setores dessa unidade, a tomada de decisões deve ser realizada em escala mais detalhada e levando em consideração a especificidade ambiental de cada setor.

A vulnerabilidade alta, localiza-se sobre a planície urbanizada de vulnerabilidade ambiental média e 
baixa, ocupando áreas com infraestrutura consolidada, como os bairros da Sacramenta, Entroncamento, Outeiro, Benguí, entre outros. Também foi identificada em áreas com planícies flúvio-lacustre e flúviomarinhas vegetadas situadas nas ilhas dentro do limite municipal.

A vulnerabilidade muito alta, corresponde a todas as áreas que apresentam infraestrutura precária e ambiente de elevada vulnerabilidade ambiental, principalmente nas planícies fluviais da ilha de Cotijuba e Mosqueiro, e em áreas urbanas que sofrem influências das marés altas e tendo dificuldade no escoamento das águas da chuva, com destaque aos bairros do Guamá e Terra firme, correspondendo a áreas de risco ambiental, de tal forma que a população habitante está muito suscetível à dinamicidade destes ambientes.

O mapa de vulnerabilidade ambiental representa importante ferramenta para a tomada de decisão, ao indicar espacialmente a dinâmica do meio natural e, consequentemente, apontar as potencialidades e as limitações, bem como os riscos das ocupações impróprias, em cada sistema ambiental.

De acordo com Becker et al. (1996), o mapa de vulnerabilidade ambiental corresponde à análise do meio físico almejando a ocupação racional e o uso sustentável dos recursos naturais. A sua utilização conjuntamente com dados e informações da caracterização social e econômica de uma região permitem importantes subsídios para o planejamento de um território.

Neste viés de análise, pode-se mostrar que a ocupação, sem diretrizes apoiadas no conhecimento do meio físico, pode acarretar consequências danosas com graves impactos ao meio ambiente.

\section{O contexto socioeconômico e a vulnerabilidade social}

O IVS se apresenta como um índice que possibilita o estudo das contradições sociais, sendo estas contradições fruto de relações desiguais que são ocasionadas por uma sociedade que é dividida em classes (SANTOS, 2015). Na tabela 3, a seguir, exibe a análise integrada das dimensões concernentes a Habitação e Saneamento, Renda, Educação e Situação social para os distritos do município de Belém.

Tabela 3: Indicadores para todas as dimensões que compõe o IVS, Caucaia, 2010.

\begin{tabular}{l|l|l|l|l|l|l}
\hline & \multicolumn{2}{l}{} \\
\hline Distritos & Habitação e Saneamento & Renda & Educação & Situação Social & IVS & Posição \\
\hline Icoaraci & 0,5554 & 0,8657 & 0,9505 & 0,6044 & $\mathbf{0 , 5 9 1 3}$ & $1^{\circ}$ \\
\hline Entroncamento & 0,7874 & 0,7492 & 0,5733 & 0,8217 & $\mathbf{0 , 6 7 9 8}$ & $2^{\circ}$ \\
\hline Benguí & 0,6560 & 0,7219 & 0,7134 & 0,6279 & $\mathbf{0 , 7 3 2 9}$ & $3^{\circ}$ \\
\hline Sacramenta & 0,9203 & 0,8352 & 0,6292 & 0,9202 & $\mathbf{0 , 7 3 3 1}$ & $4^{\circ}$ \\
\hline Belém & 0,5681 & 0,6535 & 0,5624 & 0,5812 & $\mathbf{0 , 7 4 4 0}$ & $5^{\circ}$ \\
\hline Guamá & 0,8991 & 0,7696 & 0,8362 & 0,9046 & $\mathbf{0 , 8 2 6 2}$ & $6^{\circ}$ \\
\hline Mosqueiro & 0,8924 & 0,7754 & 0,8546 & 0,8900 & $\mathbf{0 , 8 5 2 4}$ & $7^{\circ}$ \\
\hline Outeiro & 0,7939 & 0,6766 & 0,6992 & 0,7629 & $\mathbf{0 , 8 5 3 1}$ & $8^{\circ}$ \\
\hline
\end{tabular}

Fonte: Censo Demográfico do IBGE (2010).

Observa-se que Icoaraci deteve os melhores índices relativos em todas as dimensões, e consequentemente em relação ao IVS como um todo, sendo seguido por Entroncamento e Benguí. Na contramão, os distritos que obtiveram os maiores valores de IVS foram Outeiro, Mosqueiro, Guamá e Belém possuindo, as populações desses locais maior propensão a sofrer perda de bem-estar, uma vez que detêm menor dotação de ativos relacionados às condições de renda, educação, habitação e saneamento. 
Importante mencionar que nos distritos Outeiro, Mosqueiro, Guamá e Belém parcela significativa da população, sendo esta região do município carente de serviços públicos ligados ao abastecimento de água, esgotamento sanitário, coleta de lixo e educação, apresentando também baixa renda domiciliar per capita.

Ressalta-se que Outeiro, distrito que possui o maior IVS, possui um contingente populacional em torno de 31.000 habitantes. O Distrito de Outeiro é uma localidade balneária situada na Ilha de Caratateua (conhecida como Outeiro), próxima ao Distrito de Icoaraci, todos pertencentes ao Município de Belém. Suas praias de água doce são banhadas pela Baía do Guajará, e a proximidade a Belém (18 km por rodovia) juntamente com a facilidade de seus acessos, fazem com que essas praias sejam bastante procuradas em fins de semana, feriados e férias. Por sua vez, o distrito sede ainda possui algumas áreas classificadas como rurais ou em processo de urbanização, as quais não são servidas por infraestrutura urbana adequada.

O Distrito de Icoaraci, o que possui o melhor IVS, por sua localização geográfica, também foi objetos de políticas públicas territoriais, tendo em vista que em seu espaço foram implantadas um conjunto de indústrias, tendo como consequência um afluxo populacional acelerando o processo de urbanização, produzindo um espaço segregado, delimitando, redefinindo o espaço urbano. O distrito apesar de possuir uma estrutura industrial capaz de fazer inveja a qualquer município paraense, em Icoaraci ainda persiste o ar provinciano e o clima sereno e bucólico de suas ruas e praças e de sua população.

A Figura 4 exibe a distribuição territorial do IVS em nível de setores censitários, verificando-se que o padrão do IVS identificado em nível de distritos se repete parcialmente quando se analisa uma unidade geográfica de menor dimensão, no caso os setores censitários.

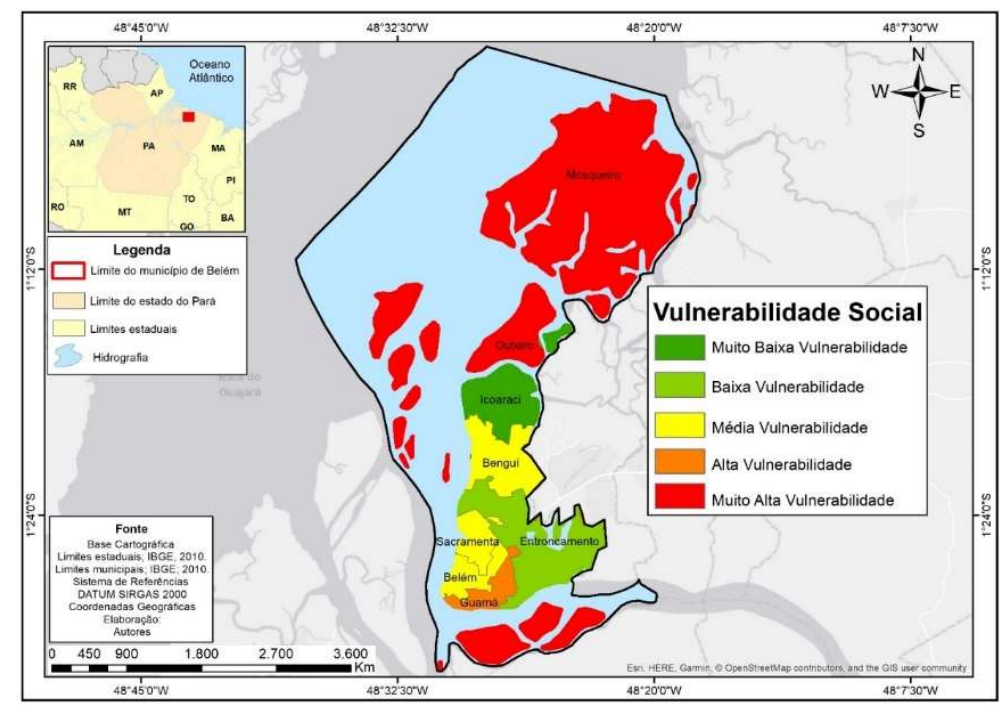

Figura 4: Mapa de vulnerabilidade Social do município de Belém/PA.

Analisando a referida figura se verifica que os distritos do Entroncamento e Icoaraci foram classificadas como tendo muito baixa e baixa vulnerabilidade social, embora alguns setores tenham sido qualificados como possuindo alta vulnerabilidade quando se refere ao mapa de vulnerabilidade ambiental, evidenciando a falta de planejamento ambiental no município.

Enquanto isto, os distritos do Guamá, Mosqueiro e Outeiro tiveram suas populações classificadas como de alta e muito alta vulnerabilidade social, enquanto que Belém, Benguí e Sacramenta registrou setores 
qualificados com médio IVS. A população destes distritos correspondeu em 2010 a 1.100 .964 pessoas ou 79\% do total do município.

A Tabela 4 mostra a divisão populacional dos distritos de Belém segundo a classificação do IVS. Em síntese, verifica-se que 292.635 (21\%) pessoas residem em condições de muito baixa e baixa vulnerabilidade, 1.029.001 (73,84\%) em situação de média e alta vulnerabilidade e 71,936 (5,6\%) pessoas moram em situação de muito alta vulnerabilidade.

Tabela 4: População segundo às classes de vulnerabilidade do IVS, Belém, 2010.

\begin{tabular}{|c|c|c|c|c|c|c|c|c|c|c|c|}
\hline \multirow{3}{*}{ Distritos } & \multicolumn{10}{|c|}{ Classes de vulnerabilidade } & \multirow{3}{*}{ Total } \\
\hline & \multicolumn{2}{|c|}{ Muito Baixa } & \multicolumn{2}{|l|}{ Baixa } & \multicolumn{2}{|l|}{ Média } & \multicolumn{2}{|l|}{ Alta } & \multicolumn{2}{|c|}{ Muito Alta } & \\
\hline & N.0 & $\%$ & N.O & $\%$ & N.0 & $\%$ & N.0 & $\%$ & N.O & $\%$ & \\
\hline Belém & 0 & 0,00 & 0 & 0,00 & 144.948 & 21,12 & 0 & 0,00 & 0 & 0,00 & 144.948 \\
\hline Benguí & 0 & 0,00 & 0 & 0,00 & 284.670 & 41,48 & 0 & 0,00 & 0 & 0,00 & 284.670 \\
\hline Entroncamento & 0 & 0,00 & 125.400 & 100,00 & 0 & 0,00 & 0 & 0,00 & 0 & 0,00 & 125.400 \\
\hline Guamá & 0 & 0,00 & 0 & 0,00 & 0 & 0,00 & 342.742 & 100,00 & 0 & 0,00 & 342.742 \\
\hline Icoaraci & 167.035 & 99,88 & 0 & 0,00 & 0 & 0,00 & 0 & 0,00 & 0 & 0,00 & 167.035 \\
\hline Mosqueiro & 0 & 0,00 & 0 & 0,00 & 0 & 0,00 & 0 & 0,00 & 33.232 & 46,18 & 33.232 \\
\hline Outeiro & 200 & 0,12 & 0 & 0,00 & 0 & 0,00 & 0 & 0,00 & 38.731 & 53,82 & 38.931 \\
\hline Sacramenta & 0 & 0,00 & 0 & 0,00 & 256.641 & 37,40 & 0 & 0,00 & 0 & 0,00 & 256.641 \\
\hline Total & 167.235 & 100,00 & 125.400 & 100,00 & 686.259 & 100,00 & 342.742 & 100,00 & 71.963 & 100,00 & 1.393 .599 \\
\hline
\end{tabular}

Fonte: Censo Demográfico do IBGE (2010).

O contingente populacional de muito baixa e baixa vulnerabilidade está concentrado no distrito do Entroncamento, Icoaraci e uma parcela muito pequena no distrito de Outeiro. Em contrapartida, Belém, Benguí, Sacramenta, Guamá, Mosqueiro e Outeiro tiveram suas populações com a classificação média, alta e muito alta.

Esses resultados sugerem que a distribuição espacial dos distritos com maior e menor vulnerabilidade não é homogênea. Neste prisma, vale citar que os setores com menor vulnerabilidade social se localizam em zonas de crescimento econômico, possibilitando a criação de posto de trabalho nas industriais, comércio e serviços, ocasionando uma maior circulação de pessoas, capital, mercadorias e informações, redefinindo o espaço num intenso processo de produção e (re) produção do mesmo. Tal processo ocasionou a ligação física entre a cidade de Belém e o distrito de forma continua. Esses locais no território municipal concentram parcela significativa da população de maior renda, possuindo também melhor disponibilidade de infraestrutura e maior oferta de serviços públicos, revelando assim, um quadro de desigualdades socioterritoriais presentes no município.

\section{Dinâmica natural e social: a Vulnerabilidade socioambiental}

Destaca-se que um estudo das condições de vulnerabilidade que atente para o diagnóstico das desigualdades sociais e das assimetrias ambientais de forma integrada, consente uma melhor definição de estratégias relacionadas ao planejamento territorial. Sob esse prisma, apresenta-se na Figura 5 o quadro da vulnerabilidade socioambiental do município de Belém, gerado a partir da análise combinada do mapa de vulnerabilidade social e ambiental corresponde a todas as áreas que apresentam infraestrutura precária e ambiente de elevada vulnerabilidade natural, principalmente nas planícies fluviais. 
Observando-se o referido mapa, podem-se identificar os lugares de ocorrência no município de muito alta, alta, média, baixa e muito baixa vulnerabilidade ambiental, assim como de muito alta, alta, média, baixa e muito baixa vulnerabilidade social. Verifica-se que as áreas com maior população na condição de alta vulnerabilidade social se sucedem nos locais atinentes ao sistema ambiental de planícies fluviais, que tem média e alta vulnerabilidade ambiental.

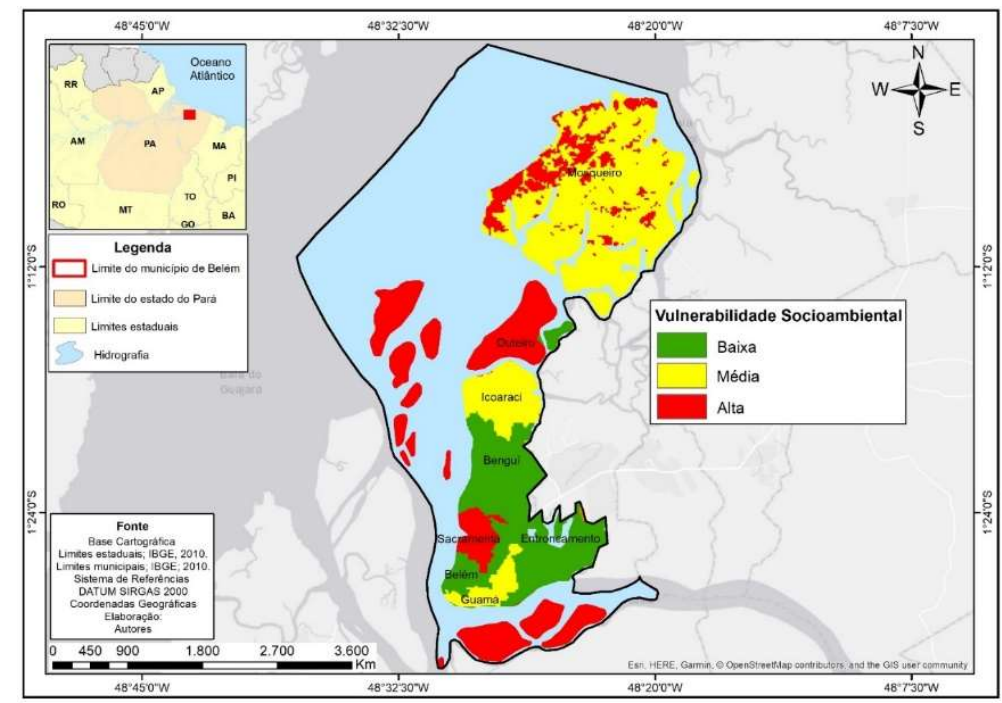

Figura 5: Vulnerabilidade socioambiental do município de Belém.

Uma possível explicação para isto é que estes lugares, via de regra, são mais acessíveis população pobre, seja porque são áreas públicas e/ou de preservação (invadidas), ou por tratar-se de locais muito desvalorizados pelo mercado imobiliário, por serem pouco propícios ocupação devido às características de risco ambiental e à falta de infraestrutura.

Segundo Zanella et al. (2013), a ocupação das planícies fluviais é um exemplo do processo histórico de exclusão social, sendo estes terrenos normalmente destinados à população socialmente vulnerável, em termos de acesso à infraestrutura urbana, educação, renda e propriedade da terra. Nestas áreas, normalmente, a população mais pobre é acometida por desastres hidroclimatológicos.

Em relação aos maciços residuais, constatou-se em Mosqueiro a presença de pequenas comunidades e sítios inseridos neste sistema ambiental, as quais estão sujeitas nos setores de maior declividade ao acometimento de deslizamentos de terra, além da existência de carência no abastecimento de água potável, configurando-se em locais com alta vulnerabilidade socioambiental, notadamente para a população de baixa renda.

Conforme Souza (2005), as principais limitações geoambientais das planícies fluviais ao processo de ocupação humana correspondem a suscetibilidade à erosão dos solos. De acordo com Deschamps (2008), existe consenso entre os especialistas de que a rápida urbanização, sem planejamento territorial, aumenta o risco de desastres naturais, uma vez que a demanda por terras para a expansão da cidade provoca o uso de áreas impróprias e expostas a riscos naturais, nomeadamente em locais propensos a deslizamentos, inundações e enchentes. Exemplo disso no perímetro municipal de Belém são as ocupações irregulares planície flúvio-marinha do Rio Guamá, onde construções precárias contribuem para a degradação ambiental, 
além de a população ficar propensa aos riscos ambientais.

\section{CONCLUSÕES}

Este trabalho objetivou propor uma metodologia para mapeamento da vulnerabilidade socioambiental, a partir da análise integrada da vulnerabilidade ambiental e da vulnerabilidade social, tendo como estudo de caso o município de Belém. Para tanto, foi necessário realizar o mapeamento dos sistemas ambientais presentes no município com base na interpretação de produtos de sensoriamento remoto e trabalho de campo, avaliando a vulnerabilidade ambiental dos mesmos.

Em termos quantitativos, constatou-se que aproximadamente $6 \%$ da área do território de Belém têm alta e muito alta vulnerabilidade ambiental à ocupação, sendo de 94 \% o percentual para os locais com média, baixa e muito baixa vulnerabilidade ambiental respectivamente. Dentro deste contexto, cita-se que a ocupação do território sem o devido conhecimento do meio físico, pode acarretar em consequências nocivas com graves impactos ao meio ambiente, e consequentemente, no bem-estar da população belenense.

Em relação aos aspectos socioeconômicos, calculou-se o Índice de Vulnerabilidade Social (IVS) para os distritos e setores censitários do município. Verificou-se que o distrito de Icoaraci obteve o melhor desempenho em todas as dimensões que compõe o IVS, e consequentemente em relação ao índice como um todo, sendo acompanhado pelo distrito do Entroncamento e Benguí. Em contrapartida, os distritos que registraram os maiores valores de IVS foram Outeiro, Mosqueiro e Guamá, detendo, as populações desses distritos maiores riscos a sofrer perda de bem-estar, gerados por possíveis alterações nos planos econômicos, sociais, políticos e ambientais. Desse modo, por meio do mapeamento da vulnerabilidade social em nível de distritos são gerados subsídios que possibilitam o planejamento de ações públicas focadas visando à diminuição das desigualdades socioterritoriais.

Enfatiza-se que por meio da análise integrada do mapa de vulnerabilidade ambiental e social, usando técnicas de geoprocessamento, foi possível localizar no território municipal os lugares de incidência de alta vulnerabilidade socioambiental, que correspondem aos locais de episódios simultâneos da vulnerabilidade ambiental e social, revelando, dessa forma, as áreas prioritárias para a intervenção de políticas públicas que objetivem a melhoria do bem-estar da população mais carente, assim como a conservação dos recursos naturais.

As áreas de ocorrência de vulnerabilidade socioambiental em Belém configuram-se, em sua maioria, pela ocupação irregular de locais com alta vulnerabilidade ambiental pela população com baixa renda e situação inferior de educação, como por exemplo, a ocupação indiscriminada de campos de dunas móveis, da planície fluvial e flúvio-marinha.

Neste bojo, destaca-se que a metodologia proposta nesta pesquisa pode ser replicada em outros municípios brasileiros almejando mapear a vulnerabilidade socioambiental, contribuindo, deste modo, com informações úteis para o planejamento territorial e a tomada de decisão ao indicar, geograficamente, as condições socioeconômicas da população, associando-as com a dinâmica e vulnerabilidade dos sistemas 
ambientais.

\section{REFERÊNCIAS}

ALMEIDA, L. Q.. Riscos ambientais e vulnerabilidades nas cidades brasileiras: conceitos, metodologias e aplicações. São Paulo: Cultura acadêmica, 2012.

BECKER, B. K.; EGLER, C. A. G.. Detalhamento da metodologia para execução do zoneamento ecológicoeconômico pelos estados da Amazônia Legal. Brasília: Secretaria de Assuntos Estratégicos do Governo Federal (SAE), 1996

CUNHA, J. M. P.; JAKOB, A. A. E.; HOGAN, D. J.; CARMO, R. L.. A vulnerabilidade social no contexto metropolitano: o caso de Campinas. In: CUNHA, J. M. P.. Novas metrópoles paulistas: população, vulnerabilidade e segregação. Campinas: Nepo/Unicamp, 2006. p.143-168.

CUNHA, L.; LEAL, C.. Natureza e sociedade no estudo dos riscos naturais. Exemplos de aplicação ao ordenamento do território no município de Torres Novas (Portugal). In: PASSOS, M. M.; CULHA, L.; JACINTO, R.. As novas geografias dos países de língua portuguesa: paisagens, territórios e políticas no Brasil e em Portugal. São Paulo: Geografia em movimento, 2012. p.47-66.

CUTTER, S.; MITCHELL, J.; SCOTT, M.. Revealing the vulnerability of people and places: a case study of Georgetown County, South Carolina. Annals of the Association of American Geographers, v.4, n.90, p.713-737, 2000.

DESCHAMPS, M. V.. Estudo sobre a vulnerabilidade socioambiental na Região Metropolitana de Curitiba. Revista Cadernos de Metrópole, n.19, p.191-219, 2008.

DESCHAMPS, M. V.. Vulnerabilidade socioambiental na região metropolitana de Curitiba. Tese (Doutorado em Meio Ambiente e Desenvolvimento) - Universidade Federal do Paraná, Curitiba, 2004.

FREITAS, M. I. C.; CUNHA, L.. Cartografia da vulnerabilidade socioambiental: convergências e divergências a partir de algumas experiências em Portugal e no Brasil. Revista Brasileira de Gestão Urbana, v.5, n.1, p.15-31, 2013.

IBGE. Instituto Brasileiro de Geografia e Estatística. Censo Demográfico de 2010. IBGE, 2010.

KAZTMAN, R.. Activos y estructura de oportunidades. Estudios sobre las raíces de la vulnerabilidade social en Uruguay. Montevidéu: PNUD-Uruguay, 1999.

MACEDO, C. E. G.; BASSANI, V. D. S.. Vulnerabilidade socioeconômica em Porto Alegre: Uma abordagem com análise multivariada. In: ENCONTRO NACIONAL DE ESTUDOS POPULACIONAIS, ABEP, 17. Anais. Caxambu, 2010.

MACEDO, Y. M.; PEDROSA, L. P. D.; ALMEIDA, L. Q.. Vulnerabilidade social de Natal, RN, Brasil: Operacionalização e mensuração no fenômeno no município. Revista Geonorte, v.1, n4, p.1.020-1.030, 2012.
MARICATO, E.. Conhecer para resolver a cidade ilegal. In: CASTRIOTA, L. B.. Urbanização Brasileira: redescobertas. Belo Horizonte: C/Arte, 2003. p.78-96.

MEDEIROS, C. N.; PETTA, R. A.; DUARTE, C. R.. Mapeamento de indicadores socioeconômicos do município de Parnamirim (RN) utilizando técnicas de geoprocessamento. Revista Geografia, v.30, n.3, p.163-181, 2005.

MENDES, J. M.; TAVARES, A. O.; CUNHA, L.; FREIRIA, S.. A vulnerabilidade social aos perigos naturais e tecnológicos em Portugal. Revista Crítica de Ciências Sociais, Coimbra, n.93, p.95-128, 2011.

OLIMPIO, J. L. S.; ZANELLA, M. E.. Emprego das geotecnologias na determinação das vulnerabilidades natural e ambiental do município de Fortaleza/CE. Revista Brasileira de Cartografia, v.1, n.64, p.01-14, 2012.

PENNA, N. A.; FERREIRA, I. B.. Desigualdades socioespaciais e áreas de vulnerabilidades nas cidades. Revista Mercator, v.13, n.3, p.25-36, 2014.

PNUD. Programa das Nações Unidas para o Desenvolvimento. Atlas do desenvolvimento humano no Brasil. Brasília: PNUD/ONU, 2013.

SANTOS, J. O.. Relações entre fragilidade ambiental e vulnerabilidade social na susceptibilidade aos riscos. Revista Mercator, v.14, n.2, p.75-90, 2015.

SANTOS, M.. A urbanização brasileira. 5 ed. São Paulo: Universidade de São Paulo, 2008.

SANTOS, R. F.; CALDEYRO, V. S.. Paisagens, condicionantes e mudanças. In: SANTOS, R. F.. Vulnerabilidade Ambiental: Desastres Naturais ou Fenômenos Induzidos?. Brasília, 2007.

SEADE. Fundação Sistema Estadual de Análise de Dados. Índice paulista de responsabilidade social. SEADE, 2012.

SEMAS. Secretaria Municipal de Assistência Social. Índice da Vulnerabilidade Social. Relatório técnico. Belém: SEMAS, 2009.

SOUZA, M. J. N.. Bases Naturais e Esboço do Zoneamento Geoambiental do Estado do Ceará. In: LIMA, L. C.; SOUZA, M. J. N.; MORAES, J. O.. Compartimentação territorial e gestão regional do Ceará. Fortaleza: FUNECE, 2000.

SOUZA, M. J. N.. Compartimentação Geoambiental do Ceará. In: SILVA, J. B.; CAVALCANTE, T. C.; DANTAS, E. W. C.. Ceará: um novo olhar geográfico. Fortaleza: Demócrito Rocha, 2005. p.127-140.

TAGLIANI, C. R. A.. A mineração na porção média da Planície Costeira do Rio Grande do Sul: estratégia para a gestão sob um enfoque de Gerenciamento Costeiro Integrado. Tese (Doutorado em Geociências) - Universidade Federal do Rio Grande do Sul, Porto Alegre, 2002. 
TOMINAGA, L. K.. Análise e Mapeamento de Risco In: TOMINAGA, L. K.; SANTORO, J.; AMARAL, R.. Desastres Naturais: conhecer para prevenir. São Paulo: Instituto Geológico, 2009. p.147-160.

TRICART, J.. Ecodinâmica. Rio de Janeiro: IBGE, 1977.
ZAHRAN, S.; BRODY, S.; PEACOCK, W.; VEDLITZ, A.; GROVER, H.. Social Vulnerability and the Natural and Built Environment: A model of flood casualties in Texas. Disasters, v.4, n.32, p.537-560, 2008.

A CBPC - Companhia Brasileira de Produção Científica (CNPJ: 11.221.422/0001-03) detém os direitos materiais desta publicação. Os direitos referem-se à publicação do trabalho em qualquer parte do mundo, incluindo os direitos às renovações, expansões e disseminações da contribuição, bem como outros direitos subsidiários. Todos os trabalhos publicados eletronicamente poderão posteriormente ser publicados em coletâneas impressas sob coordenação da Sustenere Publishing, da Companhia Brasileira de Produção Científica e seus parceiros autorizados. Os (as) autores (as) preservam os direitos autorais, mas não têm permissão para a publicação da contribuição em outro meio, impresso ou digital, em português ou em tradução. 